(2) Open Access Full Text Article

ORIGINAL RESEARCH

\title{
Knowledge Outcome of Helping Babies Breathe Training in Southern Nations, Nationalities and People's Region, Ethiopia: A Pre- and Post-Test Study
}

This article was published in the following Dove Press journal:

Research and Reports in Neonatology

\author{
Lalisa Chewaka Gamtessa (iD) \\ Kindie Mitiku Kebede (iD ${ }^{2}$ \\ 'Department of Nursing, College of \\ Health Sciences, Mizan-Tepi University, \\ Mizan-Aman, Ethiopia; ${ }^{2}$ Department of \\ Public Health, College of Health Sciences, \\ Mizan-Tepi University, Mizan-Aman, \\ Ethiopia
}

Introduction: Helping Babies Breathe (HBB) training is a key strategy to decrease neonatal mortality. The objectives of this study were to evaluate the effect of HBB on knowledge outcome and to assess the knowledge outcome in relation to different variables in Southern Nations, Nationalities and People's Region (SNNPR), Ethiopia.

Methods: A pre- and post-test study was conducted using data from HBB trainings given for health workers. The training was given for 2.5 days and the knowledge outcome was evaluated using validated 18 questions. The post-test was given immediately after the training. Data were entered into Epi Info 7 and imported to SPSS version 21. The paired sample $t$-test was used to compare pre- and post-test means. The independent sample $t$-test was used to determine the relationship between knowledge outcome with sex, education level, and health facility. One way ANOVA with post hoc test was computed for comparing the knowledge outcome of the training among different professions. The general linear model (GLM) was used to determine the main and interaction effects. The statistical significance was determined at $\mathrm{p}<0.05$.

Results: In this study, we assessed the knowledge outcome of 98 trainees. The trainees' mean knowledge score increased from $64.4 \%$ (pre-test) to $80.7 \%$ (post-test). The difference was statistically significant with $p<0.001$. Sex (pre-test $p=0.003$, post-test $p=0.005$ ) and education level (pre-test $p=0.017$, post-test $p=0.037$ ) of the trainees were significantly associated with the knowledge outcome while profession and type of health facility were not significant $(p>0.05)$. The GLM showed that the interaction effects of sex, education level, profession, and type of health facility over the knowledge outcome were non-significant $(p>0.05)$.

Conclusion: The knowledge outcome of trainees significantly improved after the HBB training. It was significantly varied with sex and education level both at pre- and post-test. Therefore, these variables need consideration when arranging HBB trainings.

Keywords: Helping Babies Breathe training, pre-test, post-test, knowledge outcome

\section{Introduction}

Helping Babies Breathe (HBB) has become the most important strategy to decrease neonatal mortality as a result of birth asphyxia. ${ }^{1-3}$ It is an evidence-based curriculum planned to improve the knowledge and skills of neonatal resuscitation in lowresource countries worldwide, where $98 \%$ of the total 3 million neonatal deaths occur every year. ${ }^{4-6}$ Evidence showed that $20 \%$ of the intrapartum-related deaths can be prevented by effective neonatal resuscitation. ${ }^{7}$

\footnotetext{
Correspondence: Lalisa Chewaka

Gamtessa

Mizan-Tepi University, Mizan-Aman,

Ethiopia

Tel +251929334173

Email lalisachewaka@gmail.com
}

Research and Reports in Neonatology 2020:10 8I-88

submit your manuscript in $\mathbf{r}$ 
The program was launched by the American Academy of Pediatrics (AAP) and its partners. The program is capable of equipping birth-attendants with knowledge and skills of saving lives from birth asphyxia through stimulation and ventilation within the first 60 seconds of life. ${ }^{8}$ Studies showed that health providers are more effective when there is frequent simulation-based education to improve their cognitive, psychomotor, and communication skills during neonatal resuscitation. ${ }^{9,10}$

Ethiopia is one of the countries with high neonatal mortality accounting for 29 per 1000 live births. ${ }^{11}$ One of the strategies to decrease this high neonatal mortality is by providing HBB training as neonatal asphyxia is a major attribute of this death. ${ }^{12,13}$ However, studies showed that knowledge outcome of HBB training varies with sex, education level, profession, and setting of the trainees. ${ }^{2,4,14-17}$ Data on the knowledge outcome of HBB training was scarce. Therefore, the objectives of this study were to evaluate the effect of HBB on knowledge outcome of the trainees and to assess its variation with sex, education level, profession, and health facility of the trainees.

\section{Methods}

The STROBE guideline for cross-sectional studies was strictly followed for reporting this study. The page numbers of each guideline components reported are presented in Supplementary File 1.

Study design: This study used secondary data of the HBB training given for health professionals at Mizan-Tepi University Teaching Hospital and Sawula General Hospital from August/2018 to August/2019. We applied a pre- and post-test study to investigate the knowledge outcome of HBB training and to assess the knowledge outcome in relation to different variables.

Study Setting and Period: This pre- and post-test study was conducted in the two HBB training centers in SNNPR of Ethiopia. The two centers of training were Mizan-Tepi University Teaching Hospital and Sawula General Hospital which are $585 \mathrm{Km}$ and $514 \mathrm{~km}$ away from Addis Ababa, respectively. This study included HBB trainings which were given in 2018 and 2019. The data were collected from March 5-20, 2020.

\section{Study Population, Inclusion and Exclusion Criteria}

The study population was health care workers (Nurses, Midwives, Health officers, and Anesthetists) who took
HBB training in 2018 and 2019. All trainees who completed the training were included. Trainees who took the pre-test and missed the post-test were excluded.

Participants and a Course structure: The training was given by grouping participants into five groups as each group should not exceed 20 trainees irrespective of their education level, profession, sex, and type of health facility. The second edition of HBB training course was given for 2 and half days. The training began with orienting different materials to the trainees followed by providing the pre-test consisting of 18 multiple choice questions. These questions were AAP's previously validated HBB knowledge assessment tool. ${ }^{18}$ Then, the trainees completed the course using the action plan (sequences of steps to help the babies breathe), learner work-books, newborn simulators, and bag-mask ventilation equipment. After completion of the training, the post-test was given using the same questions used during the pre-test. At the end, only those trainees who scored $\geq 80 \%$ ( 15 of 18 questions) were certified for the successful completion of the training as per protocol. ${ }^{1}$

\section{Study Variables}

Dependent and Independent Variables

Knowledge outcome (pre- and post-test result) of the HBB training was the dependent variable while; sex, education level, profession, and health facility of the trainees were the independent variables.

\section{Data Source and Measurement of Variables}

Knowledge was measured using AAP's previously validated HBB knowledge assessment tool consisting of 18 multiple choice questions. The score of each participant was converted to $100 \%$ and treated as continuous variable. Sex (male and female), education level (diploma and degree), type of health facility (Health Center and Hospital), and profession (Nurse, Midwife, Health Officer, and Anesthetist) were treated as categorical variables. The data were obtained from the reporting documents of HBB trainings deposited at Mizan-Tepi University Educational Development Center (EDC) which is responsible for coordinating the HBB trainings.

\section{Data Collection Procedure}

The data were collected through reviewing the report documents of the HBB training by using the data extraction checklists comprising variables of interest. The data extraction checklists were included as Supplementary File 2. 
Data analysis: The extracted data were entered into Epi Info 7 and imported to SPSS version 21 for data cleaning and analysis. Descriptive statistics (mean and standard deviation) were computed for both pre- and post-test. The trainees' scores for each time point were used regardless of whether they passed or failed the test. The paired sample $t$-test was used to compare the mean difference between pre- and post-test. An independent sample $t$-test was computed to examine the difference in the knowledge outcome of HBB based on sex, education level, and health facility of the trainees. We used one-way ANOVA with a post hoc test to check the differences in achievement among different professions; Nurses, Midwives, Anesthesia, and Health Officers. Finally, the GLM was used to determine the main and interaction effects of independent variables over knowledge outcome. The statistical significance was determined at $p<0.05$.

\section{Results}

\section{Characteristics of Study Participants}

This study included 98 participants. The characteristics of study participants are presented in Table 1 . As presented in Table 1, more than half of the trainees were female $(67.3 \%)$, from the health centers $(52 \%)$, degree holders (61.2\%), and Midwives in profession (56.1\%) (Table 1).

\section{Overall Knowledge Outcome of the Training}

Trainees' mean knowledge score increased from $64.4 \%$ (pre-test) to $80.7 \%$ (post-test). The mean knowledge score difference was 16.3 and this difference was statistically significant with $\mathrm{p}<0.001, \mathrm{CI}(13.4-19.2)$. Out of 98 total trainees, $60(61.2 \%)$ of them scored a pass mark and the rest $38(38.8 \%)$ failed to score the pass mark.

\section{Knowledge Outcome in Relation to Sex, Education Level, Health Facility and Profession of the Trainees}

There was noticeable difference between pre- and post-test results of the HBB training based on sex, and education level. However, the difference between pre- and post-test result according to health facility type was virtually negligible (Table 2). The Anesthetists and the health officer had higher mean knowledge score at post-test but all professions scored nearly similar mean knowledge score at pretest (Figure 1).

The $t$-test result showed that there was statistically a significant mean knowledge difference according to sex (pre-test ( $\mathrm{t}(96)=03.07, p=0.003)$ and post-test ( $\mathrm{t}(96)$ $=2.9, p=0.005)$ ). Similarly, there was a significant mean
Table I Characteristics of Study Participants in SNNPR, Ethiopia

\begin{tabular}{|c|c|c|}
\hline \multicolumn{2}{|l|}{ Variables } & \multirow{3}{*}{$\begin{array}{l}\mathbf{N}(\%) \\
32(32.7) \\
66(67.3)\end{array}$} \\
\hline Sex & Male & \\
\hline & Female & \\
\hline \multirow[t]{2}{*}{ Health facility } & Hospital & $47(48)$ \\
\hline & Health center & $51(52)$ \\
\hline \multirow[t]{2}{*}{ Education level } & Degree & $60(6 \mid .2)$ \\
\hline & Diploma & $38(38.8)$ \\
\hline \multirow[t]{4}{*}{ Profession } & Nurses & $30(30.6)$ \\
\hline & Midwifes & $55(56.1)$ \\
\hline & Health officers & $9(9.2)$ \\
\hline & Anesthetists & $4(4.1)$ \\
\hline
\end{tabular}

knowledge difference in relation to education level both at, pre-test $(\mathrm{t}(96)=2.4, p=0.017)$ and post-test $(\mathrm{t}(96)=2.1$, $p=0.037)$. However, there was no significant difference in knowledge outcome in relation to the type of health facility (Table 3).

The one way ANOVA with post hoc test showed that there was non-significant difference in knowledge outcome among different professions (Table 4).

\section{General Linear Model Analysis Results (Main and Interaction Effects)}

The univariate GLM analysis showed that sex $(\mathrm{F}(1,96)$ $=4.06, p=0.047)$ and education level $(\mathrm{F}(1,96)=4.9$, $p=0.030$ ) were significantly associated with the knowledge outcome at pre-test. However, these variables were nonsignificant at post-test $(p>0.05)$. Furthermore, the multivariate GLM analysis revealed that the interaction between independent variables (sex, education level, profession, and type of health facility) over the knowledge outcome was non-significant $(p>0.05)$ (Tables 5 and 6).

\section{Discussion}

This pre- and post-test study aimed to provide insights about the effect of HBB training on the knowledge outcome of the trainees immediately after the training. To the level of the investigators' knowledge, this study was the first study in SNNPR.

The study showed that the overall mean knowledge score of the trainees was significantly improved after the HBB training. Our finding is in line with study findings conducted in developing and developed countries ${ }^{2,14-16}$ and health care workers at hospitals in Rwanda. ${ }^{19}$ However, one third of our trainees failed to score the pass mark. The lower baseline knowledge of HBB might 
Table 2 Descriptive Statistics of Pre- and Post-Test Results of HBB Training According to Sex, Education Level, and Health Facility in SNNPR, Ethiopia

\begin{tabular}{|c|c|c|c|c|c|}
\hline & & Mean & Std. Deviation & Minimum & Maximum \\
\hline \multicolumn{6}{|l|}{ Sex } \\
\hline \multirow[t]{2}{*}{ I. Male } & I. Pre-test & 71.9 & 14.2 & 44 & 94 \\
\hline & 2. Post-test & 86.5 & 11.7 & 56 & 100 \\
\hline \multirow[t]{2}{*}{ 2. Female } & I. Pre-test & 60.8 & 17.8 & 27 & 100 \\
\hline & 2. Post-test & 77.9 & 14.8 & 43 & 100 \\
\hline \multicolumn{6}{|l|}{ Education level } \\
\hline \multirow[t]{2}{*}{ I Degree } & I. Pre-test & 67.7 & 18.2 & 27 & 100 \\
\hline & 2. Post-test & 83.1 & 13.9 & 43 & 100 \\
\hline \multirow[t]{2}{*}{ 2. Diploma } & I. Pre-test & 59.2 & 14.9 & 28 & 94 \\
\hline & 2. Post-test & 76.9 & 14.5 & 43 & 100 \\
\hline \multicolumn{6}{|l|}{ Health Facility } \\
\hline \multirow[t]{2}{*}{ I. Hospital } & I. Pre-test & 64.8 & 14.3 & 39 & 89 \\
\hline & 2. Post-test & 82.2 & 13.7 & 50 & 100 \\
\hline \multirow[t]{2}{*}{ 2. Health Center } & I. Pre-test & 64.1 & 20.0 & 27 & 100 \\
\hline & 2. Post-test & 79.4 & 150 & 43 & 100 \\
\hline
\end{tabular}

contribute to failure to score the pass mark. Though this deserves further studies, incorporation of HBB contents in pre-service training may increase the knowledge which in turn may reduce the failure rate.

As the independent sample $t$-test showed, the knowledge outcome of the training was significantly varied by sex both at pre-test $(\mathrm{MD}=11.0)$ and post-test $(\mathrm{MD}=8.5)$. Though non-significant at pre-test, other studies also reported that the knowledge outcome of the trainees significantly varied by sex. ${ }^{20,21}$

Knowledge outcome of HBB training significantly varied with education level of trainees both at pre-test $(\mathrm{MD}=$ $8.5)$ and post-test $(\mathrm{MD}=6.2)$. This finding is comparable with other studies conducted on different nursing professionals. $^{22,23}$ In the current study, the degree holder trainees had better knowledge outcome compared to

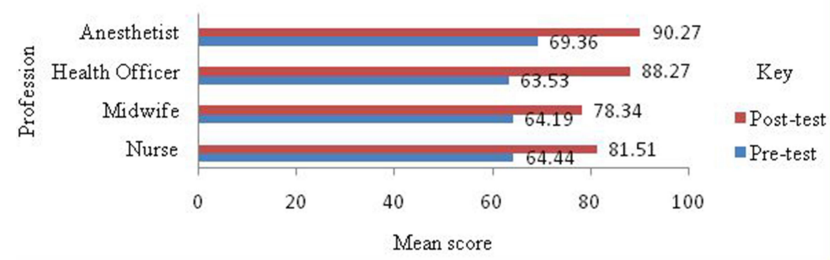

Figure I The Knowledge outcome according to profession of the trainees in SNNPR, Ethiopia. diploma holders at both pre- and post-test. The high mean knowledge score by degree holders might be due to the depth and years of study in pre-service training. In addition to the HBB training, upgrading diploma holders with formal education and continuous professional development may narrow the gap in knowledge outcome. However, this should be cautiously interpreted as all potential confounders were not controlled.

The one way ANOVA analysis showed that the knowledge outcome was not significantly varied with different professions. Absence of significant knowledge outcome variation with different professions might be due to the updated nature of the $\mathrm{HBB}$ training contents. As the updated contents of HBB training were not covered by pre-service training, all trainees may have similar exposure irrespective of their professions. On the contrary, a study finding in Honduras hospital revealed that knowledge outcome varied between nurses and physicians. The study in Honduras hospital revealed that Physicians showed higher mean knowledge score than nurses at pre-test. But, both professions showed a significant improvement at post-test. A high score in the pre-test among physicians might be attributed to previous resuscitation training with simulation in Honduras hospital. ${ }^{14}$

Overall, the knowledge outcome of trainees significantly improved after the HBB training. The improvement 
Table 3 The Knowledge Outcome in Relation to Sex, Education Level, and Health Facility in SNNPR, Ethiopia

\begin{tabular}{|c|c|c|c|c|c|c|c|c|}
\hline & \multicolumn{3}{|c|}{ Levine's Test for Equality of Variances } & \multicolumn{5}{|c|}{$t$-Test for Equality of Means } \\
\hline & \multirow[t]{2}{*}{$\mathbf{F}$} & \multirow[t]{2}{*}{ Sig. } & \multirow[t]{2}{*}{$\mathbf{t}$} & \multirow[t]{2}{*}{ df } & \multirow[t]{2}{*}{ Sig (2- Tailed) } & \multirow[t]{2}{*}{ Mean Difference } & \multicolumn{2}{|l|}{$95 \% \mathrm{Cl}$} \\
\hline & & & & & & & Lower & Upper \\
\hline \multicolumn{9}{|l|}{ I. Sex } \\
\hline Pre-test & 0.8 & 364 & 3.1 & 96 & $0.003^{*}$ & 11.0 & 3.9 & 18.2 \\
\hline Post-test & 1.9 & 0.176 & 2.9 & 96 & $0.005^{*}$ & 8.5 & 2.6 & 14.5 \\
\hline \multicolumn{9}{|l|}{ 2. Education level } \\
\hline I. Pre-test & 2.7 & 0.106 & 2.4 & 96 & $0.017^{*}$ & 8.5 & 1.5 & 15.5 \\
\hline 2. Post-test & 0.3 & 0.576 & 2.1 & 96 & $0.037^{*}$ & 6.2 & 0.4 & 12.0 \\
\hline \multicolumn{9}{|l|}{ 3. Health Facility } \\
\hline I. Pre-test & 8.1 & 0.005 & 0.2 & 90.5 & 0.848 & 0.7 & -6.4 & 7.6 \\
\hline 2. Post-test & 0.9 & 0.345 & 1.0 & 96 & 0.333 & 2.8 & -2.9 & 8.6 \\
\hline
\end{tabular}

Note: *Significant at $\mathrm{p}<0.05$.

Abbreviations: $\mathrm{MD}$, mean difference; $\mathrm{Cl}$, confidence interval; $\mathrm{df}$, degree of freedom.

Table 4 Post Hoc Tests-Multiple Comparisons Among Mean Score of Different Professions in SNNPR, Ethiopia

\begin{tabular}{|c|c|c|c|c|c|c|c|}
\hline \multirow{2}{*}{$\begin{array}{l}\text { Dependent } \\
\text { Variables }\end{array}$} & \multirow{2}{*}{$\begin{array}{l}\text { (I) Profession of } \\
\text { Trainee }\end{array}$} & \multirow{2}{*}{$\begin{array}{l}\text { (J) Profession of } \\
\text { Trainee }\end{array}$} & \multirow{2}{*}{$\begin{array}{l}\text { Mean Difference } \\
(I-J)\end{array}$} & \multirow{2}{*}{$\begin{array}{l}\text { Std. } \\
\text { Error }\end{array}$} & \multirow[t]{2}{*}{ Sig. } & \multicolumn{2}{|c|}{ 95\% Confidence Interval } \\
\hline & & & & & & $\begin{array}{l}\text { Lower } \\
\text { Bound }\end{array}$ & $\begin{array}{l}\text { Upper } \\
\text { Bound }\end{array}$ \\
\hline \multirow[t]{12}{*}{ Pre-test } & \multirow[t]{3}{*}{ Nurse } & Midwife & 0.3 & 3.6 & 1.000 & -9.3 & 9.8 \\
\hline & & Health Officer & 0.9 & 6.1 & 0.999 & -15.05 & 16.9 \\
\hline & & Anesthesia & -4.9 & 8.5 & 0.938 & -27.3 & 17.4 \\
\hline & \multirow[t]{3}{*}{ Midwife } & Nurse & -0.3 & 3.6 & 1.000 & -9.8 & 9.3 \\
\hline & & Health Officer & 0.7 & 5.7 & 0.999 & -14.4 & 15.8 \\
\hline & & Anesthesia & -5.2 & 8.3 & 0.924 & -26.9 & 16.6 \\
\hline & \multirow[t]{3}{*}{ Health Officer } & Nurse & -0.9 & 6.1 & 0.999 & -16.9 & 15.1 \\
\hline & & Midwife & -0.7 & 5.7 & 0.999 & -15.8 & 14.4 \\
\hline & & Anesthesia & -5.8 & 9.6 & 0.930 & -31.1 & 19.4 \\
\hline & \multirow[t]{3}{*}{ Anesthesia } & Nurse & 4.9 & 8.5 & 0.938 & -17.4 & 27.2 \\
\hline & & Midwife & 5.2 & 8.3 & 0.924 & -16.6 & 26.9 \\
\hline & & Health Officer & 5.8 & 9.6 & 0.930 & -19.4 & 31.1 \\
\hline \multirow[t]{12}{*}{ Post-test } & \multirow[t]{3}{*}{ Nurse } & Midwife & 3.2 & 3.2 & 0.750 & -5.2 & 11.5 \\
\hline & & Health Officer & -6.8 & 5.3 & 0.583 & -20.7 & 7.2 \\
\hline & & Anesthesia & -8.8 & 7.4 & 0.642 & -28.3 & 10.8 \\
\hline & \multirow[t]{3}{*}{ Midwife } & Nurse & -3.2 & 3.2 & 0.750 & -11.5 & 5.2 \\
\hline & & Health Officer & -9.9 & 5.0 & 0.206 & -23.1 & 3.3 \\
\hline & & Anesthesia & -11.9 & 7.2 & 0.358 & -30.9 & 7.1 \\
\hline & \multirow[t]{3}{*}{ Health Officer } & Nurse & 6.8 & 5.3 & 0.583 & -7.2 & 20.7 \\
\hline & & Midwife & 9.9 & 5.0 & 0.206 & -3.3 & 23.1 \\
\hline & & Anesthesia & -2.0 & 8.4 & 0.995 & -24.1 & 20.1 \\
\hline & \multirow[t]{3}{*}{ Anesthesia } & Nurse & 8.8 & 7.4 & 0.642 & -10.8 & 28.3 \\
\hline & & Midwife & 11.9 & 7.2 & 0.358 & -7.1 & 30.9 \\
\hline & & Health Officer & 2.0 & 8.4 & 0.995 & -20.1 & 24.1 \\
\hline
\end{tabular}


Table 5 GLM Analyses Result of the Test Between-Subjects Effects

\begin{tabular}{|c|c|c|c|c|c|c|}
\hline \multicolumn{2}{|l|}{ Variables } & \multirow{3}{*}{$\begin{array}{l}\text { Sum of Squares } \\
1036.3 \\
165.9\end{array}$} & \multirow{3}{*}{$\begin{array}{l}\text { df } \\
1 \\
\end{array}$} & \multirow{3}{*}{$\begin{array}{l}\text { Mean Square } \\
1036.3 \\
165.9\end{array}$} & \multirow{3}{*}{$\begin{array}{l}\mathbf{F} \\
4.1 \\
0.9\end{array}$} & \multirow{3}{*}{$\begin{array}{l}\text { Sig. } \\
0.047^{* *} \\
0.360\end{array}$} \\
\hline Sex & Pre-test & & & & & \\
\hline & Post-test & & & & & \\
\hline \multirow[t]{2}{*}{ Health Facility } & Pre-test & 108.1 & 1 & 108.1 & 0.4 & 0.517 \\
\hline & Post-test & 163.9 & I & 163.9 & 0.8 & 0.362 \\
\hline \multirow[t]{2}{*}{ Education level } & Pre-test & 1248.8 & I & 1248.8 & 4.9 & $0.030 * *$ \\
\hline & Post-test & 435.3 & 1 & 435.3 & 2.2 & 0.140 \\
\hline \multirow[t]{2}{*}{ Profession } & Pre-test & 1258.9 & 3 & 419.6 & 1.6 & 0.186 \\
\hline & Post-test & 451.7 & 3 & 150.6 & 0.8 & 0.514 \\
\hline \multirow[t]{2}{*}{ Sex* Health Facility } & Pre-test & 55.6 & I & 55.6 & 0.2 & 0.642 \\
\hline & Post-test & 60.8 & 1 & 60.8 & 0.3 & 0.579 \\
\hline \multirow[t]{2}{*}{ Sex* Education level } & Pre-test & 309.5 & I & 309.5 & 1.2 & 0.274 \\
\hline & Post-test & 18.6 & I & 18.6 & 0.1 & 0.758 \\
\hline \multirow[t]{2}{*}{ Sex $*$ Profession } & Pre-test & 305.1 & 3 & 101.7 & 0.4 & 0.755 \\
\hline & Post-test & 11.8 & 3 & 3.9 & 0.0 & 0.996 \\
\hline \multirow[t]{2}{*}{ Health Facility $*$ Education level } & Pre-test & 60.9 & I & 60.9 & 0.2 & 0.627 \\
\hline & Post-test & 0.0 & I & 0.0 & 0.0 & 0.991 \\
\hline \multirow[t]{2}{*}{ Health Facility $*$ Profession } & Pre-test & 339.5 & 2 & 169.7 & 0.7 & 0.517 \\
\hline & Post-test & 354.1 & 2 & 177.1 & 0.9 & 0.408 \\
\hline \multirow[t]{2}{*}{ Education level $*$ Profession } & Pre-test & 535.4 & 2 & 267.7 & I.I & 0.356 \\
\hline & Post-test & 53.5 & 2 & 26.7 & 0.1 & 0.872 \\
\hline \multirow[t]{2}{*}{ Sex* Health Facility * Education level } & Pre-test & 190.9 & I & 190.9 & 0.8 & 0.390 \\
\hline & Post-test & 14.4 & I & 14.4 & 0.1 & 0.787 \\
\hline \multirow[t]{2}{*}{ Sex $*$ Health Facility $*$ Profession } & Pre-test & 718.6 & 2 & 359.3 & 1.4 & 0.251 \\
\hline & Post-test & 378.5 & 2 & 189.2 & 1.0 & 0.384 \\
\hline \multirow[t]{2}{*}{ Sex $*$ Education level $*$ Profession } & Pre-test & 461.6 & I & 461.6 & 1.8 & 0.183 \\
\hline & Post-test & 326.9 & I & 326.856 & 1.7 & 0.200 \\
\hline
\end{tabular}

Notes: *Interaction between variables. ${ }^{* *}$ Significant at $\mathrm{P}<0.05$.

Table 6 GLM Analysis Result of Multivariate Tests

\begin{tabular}{|c|c|c|c|c|c|c|}
\hline Variables & Value & $\mathbf{F}$ & Hypothesis df & Error df & Sig. & Partial Eta Squared \\
\hline Sex & 1.0 & 2.0 & 2.0 & 75.0 & 0.139 & 0.1 \\
\hline Education level & 0.9 & 2.5 & 2.0 & 75.0 & 0.092 & 0.1 \\
\hline Health Facility & 1.0 & 0.4 & 2.0 & 75.0 & 0.653 & 0.0 \\
\hline Profession & 0.9 & 1.7 & 6.0 & 150.0 & 0.132 & 0.1 \\
\hline Sex * education level & 1.0 & 0.7 & 2.0 & 75.0 & 0.519 & 0.0 \\
\hline Sex $*$ Health Facility & 1.0 & 0.171 & 2.0 & 75.0 & 0.843 & 0.0 \\
\hline Sex*Profession & 1.0 & 0.228 & 6.0 & 150.0 & 0.967 & 0.0 \\
\hline Education level $*$ Health Facility & 1.0 & 0.165 & 2.0 & 75.0 & 0.848 & 0.0 \\
\hline Education level $*$ Profession & 1.0 & 0.574 & 4.0 & 150.0 & 0.682 & 0.0 \\
\hline Health Facility $*$ Profession & 1.0 & 0.5 & 4.0 & 150.0 & 0.733 & 0.0 \\
\hline Sex $*$ education level $*$ Health Facility & 1.0 & 0.8 & 2.0 & 75.0 & 0.469 & 0.0 \\
\hline Sex* Health Facility Profession & 0.9 & 1.0 & 4.0 & 150.0 & 0.409 & 0.0 \\
\hline
\end{tabular}

Note: *Interaction between variables. 
varied with sex and education level both at pre- and posttest. However, GLM result showed that the variation due to sex and education level was not statistically significant at post-test. This may indicate that the HBB training might have narrowed the knowledge difference due to these variables at post-test. In addition, the GLM analysis result showed that the simultaneous effects of sex, education level, profession, and type of health facility on knowledge outcome were not statistically significant.

\section{Strengths and Limitations of the Study}

This study is the first study on the knowledge outcome of HBB training in SNNPR. It used validated and standardized tools to assess the knowledge outcome of HBB training. ${ }^{18}$ The results of this study may not be representative to all regions in Ethiopia due to non-probability sampling methods applied in this study. The knowledge outcome difference due to variables like years of clinical experience, and previous related training were not assessed because these variables were not recorded in the reporting document of the HBB training registration book. In this study, we evaluated the immediate knowledge outcome of HBB training. Knowledge retention, clinical behavior and newborn outcomes were not studied. Therefore, future studies on the effect of HBB training in this study area should focus on the long-term effect of the training. Prior studies showed that knowledge and skill retention after training usually decline with time elapse. ${ }^{3,15,24}$ However, there are several strategies to retain knowledge and skill such as refresher training, adding videos during HBB training. $3,15,24,25$

\section{Conclusion}

The knowledge outcome of trainees significantly improved after the HBB training. The knowledge outcome significantly varied with sex and education level both at pre- and post-test therefore, programmers and stake holders should consider these variables when arranging HBB trainings. In spite of a significant improvement in knowledge outcome, one third of the trainees failed to score the pass mark and this deserves further studies.

\section{Abbreviations}

AAP, American Academy of Pediatrics; ANOVA, Analysis of Variances; HBB, Helping Babies Breath;
EDC, Educational Development Center; GLM, General Linear Model.

\section{Data Sharing Statement}

All the datasets used and/or analyzed during the current study are available from primary author (Lalisa Chewaka) on a reasonable request (lalisachewaka@gmail.com).

\section{Ethics Approval and Informed Consent}

Permission letter was obtained from Mizan-Tepi University College of Health Sciences, Academic and Research Directorate with Ref No.: MTU/CHS/981/12. Permission was also obtained from EDC Office to access data of HBB trainings. No identifiable data was accessed in this research. As we used secondary data, the consent to participate was not applicable.

\section{Acknowledgments}

We would like to thank Mizan-Tepi University, College of Health Sciences for providing support during the study.

\section{Author Contributions}

All authors made substantial contributions to conception and design, acquisition, analysis, and interpretation of data. All authors also took part in drafting the article, revising it critically for important intellectual content, agreed to submit to the current journal, gave final approval of the version to be published, and agree to be accountable for all aspects of the work.

\section{Funding}

There is no funding to report.

\section{Disclosure}

The authors declare that they have no competing interests for this work.

\section{References}

1. American Academy of Pediatrics. Helping Babies Breathe, 2nd Edition Update Guide What's New on the HBB 2 nd Edition Action Plan?; 2015:1-9. Available from: hbs.aap.org. Accessed September 21, 2020.

2. Ashish KC, Wrammert J, Nelin V, et al. Evaluation of helping babies breathe quality improvement cycle (HBB-QIC) on retention of neonatal resuscitation skills six months after training in Nepal. BMC Pediatr. 2017;17(1):1-9. doi:10.1186/s12887-017-0853-5 
3. Tabangin ME, Josyula S, Taylor KK, Vasquez JC, Kamath-Rayne BD. Resuscitation skills after helping babies breathe training: a comparison of varying practice frequency and impact on retention of skills in different types of providers. Int Health. 2018;10 (3):163-171. doi:10.1093/inthealth/ihy017

4. Atefi Y, Chen S, Farrell A, Mahmoud E. Impact of helping babies breathe training on the change in knowledge, attitude and practice among community health care workers in Jimma region, Ethiopia. Ann Glob Health. 2016;82(3):319. doi:10.1016/j.aogh.2016.04.581

5. Burstein R, Henry NJ, Collison ML, et al. Mapping 123 million neonatal, infant and child deaths between 2000 and 2017. Nature. 2019;574(7778):353-358. doi:10.1038/s41586-019-1545-0

6. Liu L, Oza S, Hogan D, et al. Global, regional, and national causes of under-5 mortality in 2000-15: an updated systematic analysis with implications for the sustainable development goals. Lancet. 2016;388 (10063):3027-3035. doi:10.1016/S0140-6736(16)31593-8

7. Wall SN, Lee AC, Niermeyer $\mathrm{S}$, et al. Neonatal resuscitation in low-resource settings: what, who, and how to overcome challenges to scale up? International Journal of Gynaecology and Obstetrics October 2009; 107 (Suppl 1): S47-S64. Int J Gynaecol Obstrt. 2010;107 (Suppl1):S47-S64. doi:10.1016/j.ijgo.2009.07.013.Neonatal

8. Singhal N, Lockyer J, Fidler H, et al. Helping babies breathe: global neonatal resuscitation program development and formative educational evaluation. Resuscitation. 2012;83(1):90-96. doi:10.1016/j. resuscitation.2011.07.010

9. Kamath-Rayne BD, Berkelhamer SK, Kc A, Ersdal HL, Niermeyer S. Neonatal resuscitation in global health settings: an examination of the past to prepare for the future. Pediatr Res. 2017;82(2):194-200. doi:10.1038/pr.2017.48

10. Ghoman SK, Patel SD, Cutumisu M, et al. Serious games, a game changer in teaching neonatal resuscitation? A review. Arch Dis Child Fetal Neonatal Ed. 2020;105(1):F98-F107. doi:10.1136/archdischild2019-317011

11. ICF EPHI (EPHI) [Ethiopia]. Ethiopian Public Health Institute (EPHI) [Ethiopia] and ICF. 2019. Ethiopia Mini Demographic and Health Survey 2019: Key Indicators. Rockville, Maryland, USA: EPHI and ICF; 2019.

12. Mengesha HG, Sahle BW. Cause of neonatal deaths in Northern Ethiopia: a prospective cohort study. BMC Public Health. 2017;17 (1):62. doi:10.1186/s12889-016-3979-8

13. Seid SS, Ibro SA, Ahmed AA, et al. Causes and factors associated with neonatal mortality in neonatal intensive care unit (NICU) of Jimma University Medical Center, Jimma, South West Ethiopia. Pediatr Health Med Ther. 2019;10:39-48. doi:10.2147/phmt.s197280

14. Seto TL, Tabangin ME, Josyula S, Taylor KK, Vasquez JC, KamathRayne BD. Educational outcomes of helping babies breathe training at a community hospital in Honduras. Perspect Med Educ. 2015;4 (5):225-232. doi:10.1007/s40037-015-0214-8
15. Draiko CV, Yamarat K, Panza A, Draleru J. Knowledge, skills and competency retention among health workers one year after completing helping babies breathe training in south Sudan. Pan Afr Med J. 2019;33:1-13. doi:10.11604/pamj.2019.33.175.17560

16. Bang A, Patel A, Bellad R, et al. Helping Babies Breathe (HBB) training: what happens to knowledge and skills over time? BMC Pregnancy Childbirth. 2016;16(1):1-12. doi:10.1186/s12884-016-1141-3

17. Vunni Draiko C, Yamarat K, Panza A, Draleru J. Evaluation of retention of knowledge, skill and competency of health workers one year after completion of the Helping Babies Breathe training program in South Sudan. F1000Research. 2019;8:167. doi:10.12688/ f1000research. 17560.2

18. American Academy of Pediatrics. Knowledge Check (HBB 2nd Edition); 2015:2. Available from: hbs.aap.org. Accessed September 21, 2020.

19. Musafili A, Ess B. Evaluating helping babies breathe: training for healthcare workers at hospitals in Rwanda: regular article. Acta Paediatr Int J Paediatr. 2013;102(1):34-38. doi:10.1111/apa.12034

20. Alghazo Y, Al M. Impact of Web-Based Training on Learning Outcomes: Gender Differences; 2017. International Journal of Science and Research Publisher. doi:10.21275/ART20172231

21. Münich D, Gneezy U, Niederle M. Gender gap in performance under competitive pressure: gender gap in performance under competitive pressure: admissions to Czech Universities. Am Econ Rev. 2011;101 (3):514-518. doi:10.1257/aer.101.3.514

22. Redhead K, Futures A, Bradshaw T. An evaluation of the outcomes of psychosocial intervention training for qualified and unqualified nursing staff working in a low-secure mental health unit. J Psychiatr Ment Health Nurs. 2011;18(1):59-66. doi:10.1111/ j.1365-2850.2010.01629.x

23. Lake T, Eileen MDM. Understanding clinical expertise: nurse education, experience, and the hospital context. Nationa Inst Heal NIH Public Access. 2011;33(4):276-287. doi:10.1002/nur.20388

24. Reisman J, Arlington L, Jensen L, Louis H, Suarez-Rebling D, Nelson BD. Newborn resuscitation training in resource-limited settings: a systematic literature review. Pediatrics. 2016;138(2): e20154490. doi:10.1542/peds.2015-4490

25. Odongkara B, Tylleskär T, Pejovic N, et al. Adding video-debriefing to helping-babies-breathe training enhanced retention of neonatal resuscitation knowledge and skills among health workers in Uganda: a cluster randomized trial. Glob Health Action. 2020;13 (1):1743496. doi:10.1080/16549716.2020.1743496
Research and Reports in Neonatology

\section{Publish your work in this journal}

Research and Reports in Neonatology is an international, peerreviewed, open access journal publishing original research, reports, editorials, reviews and commentaries on neonatal health. The manuscript management system is completely online and includes a very quick and fair peer-review system. Visit http://www.dovepress. com/testimonials.php to read real quotes from published authors. 